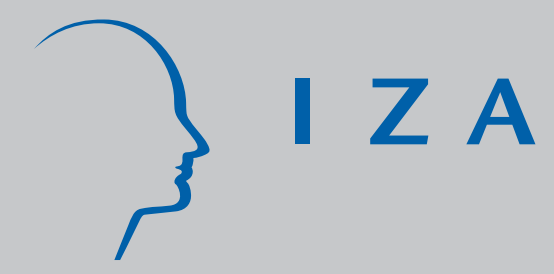

IZA DP No. 2463

Moral Hazard Contracts: Does One Size Fit All?

Alexander K. Koch

Eloïc Peyrache

November 2006 


\title{
Moral Hazard Contracts: Does One Size Fit All?
}

\author{
Alexander K. Koch \\ Royal Holloway, University of London \\ and IZA Bonn \\ Eloïc Peyrache \\ HEC School of Management, Paris
}

Discussion Paper No. 2463

November 2006

\author{
IZA \\ P.O. Box 7240 \\ 53072 Bonn \\ Germany \\ Phone: +49-228-3894-0 \\ Fax: +49-228-3894-180 \\ E-mail: iza@iza.org
}

\begin{abstract}
Any opinions expressed here are those of the author(s) and not those of the institute. Research disseminated by IZA may include views on policy, but the institute itself takes no institutional policy positions.
\end{abstract}

The Institute for the Study of Labor (IZA) in Bonn is a local and virtual international research center and a place of communication between science, politics and business. IZA is an independent nonprofit company supported by Deutsche Post World Net. The center is associated with the University of Bonn and offers a stimulating research environment through its research networks, research support, and visitors and doctoral programs. IZA engages in (i) original and internationally competitive research in all fields of labor economics, (ii) development of policy concepts, and (iii) dissemination of research results and concepts to the interested public.

IZA Discussion Papers often represent preliminary work and are circulated to encourage discussion. Citation of such a paper should account for its provisional character. A revised version may be available directly from the author. 
IZA Discussion Paper No. 2463

November 2006

\section{ABSTRACT}

\section{Moral Hazard Contracts: Does One Size Fit All?}

Incentive theory predicts that contract terms should respond to differences in agents' productivities. Firms' practice of anonymous contracts thus appears puzzling. We show that such a "one-size-fits-all" approach can be reconciled with standard agency theory if careers are marked by frequent transitions between employers, and agents have career concerns because complete long-term contracts are not feasible.

JEL Classification: D80, J33, L14, M12

Keywords: anonymous contracts, career concerns, incentive contracts, reputation

Corresponding author:

Alexander K. Koch

Royal Holloway, University of London

Dept. of Economics

Egham TW20 0EX

United Kingdom

E-mail: Alexander.Koch@rhul.ac.uk 


\section{Introduction}

Incentive theory predicts that contract terms should respond to differences in agents' productivities. In practice however, firms tend to offer contracts that are anonymous rather than tailored to individual characteristics (see Baker et al., 1994; Bhattacharyya and Lafontaine, 1995), which appears to be puzzling. The prevalence of anonymous contracts is hard to explain only with legal restrictions, transaction costs (Levy and Vukina, 2002), or fairness considerations. This note shows that a "one-size-fits-all" approach can result from strategic considerations even in the absence of such constraints. We use a standard agency model incorporating two extensions that are relevant to labor market settings. First, careers frequently involve transitions to other employers 11 Second, individuals' behavior is influenced by career concerns (Holmström, 1982/99) because complete (long-term) contracts are not feasible..$^{2}$

All else equal, tailoring contracts to information that the contracting parties have about productivity reduces the cost of providing incentives. However, tailoring also changes future labor market outcomes by providing a signal that reduces uncertainty about the individual's productivity. On the one hand, implicit incentives are weakened because market assessment of the agent relies less on his observed performance. On the other hand, competitors can more easily identify talented individuals and the cost of retaining a productive worker increases for the firm. We show that these two adverse effects outweigh the reduction in total incentive cost whenever there is sufficient heterogeneity in workers' productivities, so that an anonymous "one-size-fits-all" contract emerges as the optimal arrangement.

The paper is organized as follows. Section 2 reviews the basic argument for contract heterogeneity. This framework is extended in Section 3 to derive a sufficient condition for a one-size-fits-all contract to be optimal in the presence of career concerns. Section 4 concludes our paper.

\section{The basic argument for contract heterogeneity}

Consider a simple moral hazard problem where a worker (the agent) engages in a project, which generates revenue $V>0$ for the firm (the principal) if it succeeds (state $S$ ) and zero if it fails (state

\footnotetext{
${ }^{1}$ Each month about 2.6 percent of all employed in the US switch to a new employer, accounting for roughly 40 percent of new jobs started (Fallick and Fleischman, 2004). As a result, an average worker in the US holds seven different full-time jobs during the first ten years of his career alone (Topel and Ward, 1992, p.448). Corresponding figures for the UK and Germany are four and three, respectively (Dustmann and Pereira, 2005, p.19).

${ }^{2}$ Typically, in labor markets parties lack full pre-commitment power (slavery is outlawed). If the parties had such powers, the dynamic incentive problems would essentially collapse to static ones where career concerns play no role.
} 
$F)$. The agent can be of two different types, $\theta \in\{L, H\}$. For either type the minimum effort level $(e=0)$ leads to a success probability of $p \geq 0$. By exerting unobservable effort $(e=1)$ at private cost $\psi$, an agent of type $\theta$ increases the success probability of the project to $P_{\theta}$, where $P_{H}>P_{L}>p$. To set the stage for our analysis of the role that contracts can play in revealing information we adopt the following timing. At the time when the principal makes a take-it-or-leave-it offer to the agent both parties assign prior probability $h \in(0,1)$ to the agent being of type $H$. The principal offers a contract schedule that can make incentive pay contingent on the outcome of a screening task à la Prescott and Visscher (1980), which will reveal the agent's type to both contracting parties. Let $T_{\theta k}$ denote the transfer received by a type- $\theta$ agent in state $k \in\{S, F\}$. Either the principal offers tailored (separating) contracts $\left(T_{L k} \neq T_{H k}\right.$ for at least one state $\left.k \in\{S, F\}\right)$ or a one-size-fits-all (pooling) contract $\left(T_{L k}=T_{H k}\right.$ for $\left.k \in\{S, F\}\right)$. Work on the project starts after the screening task. Parties are risk neutral, the agent is wealth and credit constrained (preventing negative transfers) and has an outside option providing life-time utility normalized to zero.

What is the optimal contract in this setting? The agent's incentive constraint for effort $(e=1)$ is given by

$$
P_{\theta} T_{\theta S}+\left(1-P_{\theta}\right) T_{\theta F}-\psi \geq p T_{\theta S}+(1-p) T_{\theta F}, \quad \Leftrightarrow \quad T_{\theta S}-T_{\theta F} \geq \frac{\psi}{P_{\theta}-p}, \quad \theta=L, H
$$

Owing to limited liability, transfers are optimally set to $T_{\theta F}=0$ and $T_{\theta S}=\frac{\psi}{P_{\theta}-p}$ whenever effort is implemented. To focus on the interesting case where providing incentives to both worker types is indeed optimal we impose

\section{Assumption $1 \quad V>\frac{\psi}{P_{L}-p}$.}

Under Assumption 1 we have $T_{H S} \neq T_{L S}$, so the principal optimally offers separating contracts that reflect the underlying heterogeneity in productivities.

\section{Contracting in the presence of career concerns}

Let us now add a second period to the model of Section 2, in which the agent can switch to a new employer. Potential second-period employers are not aware of the agent's type and place prior probability $h$ on the worker being of type $H$. However, they observe the agent's first-period project outcome and the incentive pay before making a wage offer.

Transitions between employers are modeled as in Greenwald (1986): i) after the agent has received outside offers the incumbent principal can make a counteroffer; ii) the quit decision of the agent is 
characterized by the function

$$
q=\text { probability of quitting }=\left\{\begin{array}{cc}
\alpha & \text { for } \quad W \geq \omega \\
1 & \text { for } \quad W<\omega
\end{array}, \quad \alpha \in[0,1]\right.
$$

where $W$ is the wage a worker receives if he remains with his initial employer and $\omega$ is the wage if he quits. What matters for our result is only that the rent accruing to an agent in the future is increasing in his expected type. This is captured in reduced form by the assumption of a competitive labor market for experienced workers where a type- $\theta$ agent generates revenue $k_{\theta}$, with $\Delta k \equiv k_{H}-k_{L}>0$. Discount rates are normalized to one.

Our aim is to analyze how the second-period labor market affects the first-period contract in the standard career concerns setting where contract terms can only cover one period (e.g., Holmström, $1982 / 99)$.

Tailored (SEPARAting) COntracts: Separating contracts $\mathcal{S}(\theta)=\left[t_{\theta F}, t_{\theta S}\right], \theta \in\{L, H\}$, reveal the type of the agent. Because the incumbent firm competes with its competitors under symmetric information for the agent's service, his second-period wage equals $k_{\theta}$. Substituting into (1) $T_{\theta F}=$ $t_{\theta F}+k_{\theta}$ and $T_{\theta S}=t_{\theta S}+k_{\theta}$ and using Assumption 1 yields the transfers $t_{\theta F}=0$ and $t_{\theta S}=\frac{\psi}{P_{\theta}-p}$ as well as the expected profit:

$$
E[\Pi \mid(\mathcal{S}(L), \mathcal{S}(H))]=\left[h P_{H}+(1-h) P_{L}\right] V-\left(h \frac{P_{H}}{P_{H}-p}+(1-h) \frac{P_{L}}{P_{L}-p}\right) \psi .
$$

One-Size-Fits-All (POOling) CONTRACT: Consider now a pooling contract $\mathcal{P}$ designed to implement effort by both types of agents. Because the contract does not reveal the agent's type, the project outcome affects the second-period wage offers. The market anticipates that the incumbent firm will make a matching counteroffer to a type- $H$ agent (probability $h$ ), which will be turned down with probability $\alpha$. In contrast, no counteroffer will be made to a type- $L$ worker. Using Bayes' rule, market wage offers conditional on the project outcome are given by:

$$
\begin{aligned}
\omega_{S}=E[k \mid S, \text { accepts market offer; } \mathcal{P}] & =k_{L}+\frac{\alpha h P_{H}}{\alpha h P_{H}+(1-h) P_{L}} \Delta k, \\
\omega_{F}=E[k \mid F, \text { accepts market offer; } \mathcal{P}] & =k_{L}+\frac{\alpha h\left(1-P_{H}\right)}{\alpha h\left(1-P_{H}\right)+(1-h)\left(1-P_{L}\right)} \Delta k .
\end{aligned}
$$

This has two effects.

1. an incentive effect. A success of the project leads to an increase in second-period wage for the agent of $\omega_{S}-\omega_{F} \equiv R \Delta k$, where

$$
R \equiv \frac{\alpha h(1-h)\left(P_{H}-P_{L}\right)}{\left[\alpha h P_{H}+(1-h) P_{L}\right]\left[\alpha h\left(1-P_{H}\right)+(1-h)\left(1-P_{L}\right)\right]} .
$$


To derive the contract terms offered, substitute into (1) $T_{\theta F}=t_{F}+\omega_{F}$ and $T_{\theta S}=t_{S}+\omega_{S}$ for $\theta \in\{L, H\}$, which yields $t_{F}=0$ and $t_{S}=\max \left\{\frac{\psi}{P_{L}-p}-R \Delta k, 0\right\}$.

2. a retention effect. Because of adverse selection in the second-period labor market wages fall short of the productivity of a type- $H$ agent: $k_{H}>\omega_{S} \geq \omega_{F} \geq k_{L}$. Thus, the expected profit from being able to retain a type- $H$ agent is $h(1-\alpha)\left[k_{H}-\left(P_{H} \omega_{S}+\left(1-P_{H}\right) \omega_{F}\right)\right] \equiv$ $\operatorname{RET} \Delta k$, where

$$
R E T=h(1-h)(1-\alpha) \frac{\alpha h P_{H}\left(1-P_{H}\right)+(1-h) P_{L}\left(1-P_{L}\right)}{\left.\left[\alpha h P_{H}+(1-h) P_{L}\right)\right]\left[\alpha h\left(1-P_{H}\right)+(1-h)\left(1-P_{L}\right)\right]} .
$$

Combining the two effects yields expected profit

$$
E[\Pi \mid \mathcal{P}]=\left[h P_{H}+(1-h) P_{L}\right]\left[V-\max \left\{\frac{\psi}{P_{L}-p}-R \Delta k, 0\right\}\right]+\operatorname{RET} \Delta k .
$$

Both cost savings from reputational incentives (the incentive effect) and retention profits (the retention effect) are increasing in $\Delta k$. However, the quit probability $\alpha$ has opposite effects on retention profits and reputational incentives. For $\alpha=0$ reputational incentives vanish $(R=0)$. This stems from a standard adverse selection argument (Greenwald, 1986). Outsiders anticipate that the initial employer will match their bid and retain the agent if he is of type $H$. Because only type- $L$ agents will switch to new firms $\omega_{S}=\omega_{F}=k_{L}$. Hence, retaining a type- $H$ agent costs only $k_{L}$ so retention profits are at their maximum. In contrast, for $\alpha=1$ the initial employer can never retain the agent and there is no adverse selection: reputational incentives are at their maximum and retention profits $\operatorname{vanish}(R E T=0)$.

Comparison: Comparing separating contracts $(\mathcal{S}(L), \mathcal{S}(H))$ with pooling contract $\mathcal{P}$ provides a sufficient condition for the optimality of pooling contracts.

\section{Proposition 1}

There exists a threshold $\overline{\Delta k} \in\left[0, \frac{\psi}{R\left(P_{L}-p\right)}\right]$ such that for $\Delta k \geq \overline{\Delta k}$ the pooling contract $\mathcal{P}$ that implements effort by both types of agents is more profitable than any separating contract.

Proof. Assumption 1 implies that $(\mathcal{S}(L), \mathcal{S}(H))$ is the most profitable separating contract. Let $\Delta \Pi=$ $E[\Pi \mid \mathcal{P}]-E[\Pi \mid(\mathcal{S}(L), \mathcal{S}(H))] . \Delta \Pi<0$ for $\Delta k=0 . \Delta \Pi$ is continuous and increasing in $\Delta k$ up to the threshold $\frac{\psi}{R\left(P_{L}-p\right)}$ where reputational incentives are just sufficient to provide all incentives for free under $\mathcal{P}$. Thus, $\Delta \Pi>0$ at this threshold. Hence, by the intermediate value theorem, there exists a threshold $\overline{\Delta k} \in\left[0, \frac{\psi}{R\left(P_{L}-p\right)}\right]$ above which $\Delta \Pi>0$. Note that for $\alpha \rightarrow 0 \frac{\psi}{R\left(P_{L}-p\right)} \rightarrow \infty$. But since for $\alpha<1$ the retention profits under the pooling contract are continuously increasing in $\Delta k$, existence of a finite threshold $\overline{\Delta k}$ is guaranteed for all $\alpha \in[0,1]$. 


\section{Discussion and concluding remarks}

We have provided a rationale for why firm use one-size-fits-all contracts rather than contracts tailored to individual characteristics. Our model incorporates two key features of labor market settings: i) firms and workers interact over multiple periods; ii) restrictions on long-term contracting prevent internalizing the incentive effects of career concerns.

Clearly, not tailoring contracts to individual characteristic comes at some cost to the employer: a one-size-fits-all (pooling) contract does worse than tailored (separating) contracts in terms of total incentives required on average to make both types of agents exert effort. There are however some countervailing effects. A Pooling contract preserves uncertainty about the agent's type. The first channel through which this affects the principal's profit are the resulting reputational incentives $R \Delta k$. They allow reducing the first-period incentive pay - the required monetary incentives which is what really matters to the employer. If career concerns are sufficiently strong, the monetary implementation cost under the pooling contract becomes lower than that under separating contracts. This will happen whenever there is sufficient heterogeneity of the workforce, both in terms of productivity (large $P_{H}-P_{L}$ and large $\Delta k$ ) and in terms of the composition of the worker pool $(h(1-h)$ bounded away from 0$)$. The second channel through which uncertainty about the agent's type increases the profit under a pooling contract is the retention effect. Adverse selection in the second-period labor market allows the initial employer to retain type-H agents at a lower cost. The associated profit component $R E T \Delta k$ is also increasing in the difference in productivities for experienced agents $(\Delta k)$ and the heterogeneity of the worker pool $(h(1-h))$. 


\section{References}

Baker, George, Michael Gibbs, and Bengt Holmström, 1994, The wage policy of a firm, Quarterly Journal of Economics 109, 921-955.

Bhattacharyya, Sugato, and Francine Lafontaine, 1995, Double-sided moral hazard and the nature of share contracts, RAND Journal of Economics 26, 761-781.

Dustmann, Christian, and Sonia C. Pereira, 2005, Wage growth and job mobility in the U.K. and Germany, IZA Discussion paper No. 1586.

Fallick, Bruce, and Charles A. Fleischman, 2004, Employer-to-employer flows in the U.S. labor market: The complete picture of gross worker flows, Federal Reserve Board, Washington, DC.

Greenwald, Bruce C., 1986, Adverse selection in the labour market, Review of Economic Studies $53,325-247$.

Holmström, Bengt, 1982/99, Managerial incentive problems: A dynamic perspective, Review of Economic Studies 66, 169-182 ; originally published in: Essays in Economics and Management in Honour of Lars Wahlbeck, Helsinki, Finland.

Levy, Armando, and Tomislav Vukina, 2002, Optimal linear contracts with heterogeneous agents, European Review of Agricultural Economics 29, 205-217.

Prescott, Edward C., and Michael Visscher, 1980, Organization capital, Journal of Political Economy $88,446-461$.

Topel, Robert H., and Michael P. Ward, 1992, Job mobility and the careers of young men, Quarterly Journal of Economics 107, 439-479. 